
13 States crust), and DMM (depleted upper mantle) mantle reservoirs. The plume system feeding the

\title{
Sulfur isotope characterization of primordial and recycled sources feeding the Samoan mantle plume
}

\author{
James W. Dottin III ${ }^{* 1}$, Jabrane Labidi ${ }^{3}$, Vedran Lekic ${ }^{1}$, \\ Matthew G. Jackson" ${ }^{4}$ James Farquhar ${ }^{1,2}$
}

${ }^{*}$ Corresponding author: jdottin@umd.edu

${ }^{1}$ Department of Geology, University of Maryland, College Park, MD 20742, United States

2Earth System Science Interdisciplinary Center, College Park, MD 201742, United States

${ }^{3}$ Department of Earth, Planetary, and Space Sciences, University of California, Los Angeles, CA 90095, United States

${ }^{4}$ Department of Earth Science, University of California, Santa Barbara, CA 93106, United

4

(1)

Abstract

The Samoan islands are the type locality for the Enriched Mantle (II) reservoir that is thought to be produced from the subduction and recycling of marine sediment from upper continental crust. In addition to hosting extreme radiogenic isotope compositions from the EM II reservoir, Samoa also exhibits contributions from other mantle reservoirs in a dilute form including the EM (I) (recycled continental material), HIMU (recycled oceanic Samoan islands sits above a seismically imaged Large Low Shear Velocity Province (LLSVP) 
23 and an Ultra-Low Velocity Zone (ULVZ) that is thought to contribute, in addition to recycled 24 components, the recently discovered early-formed (primordial) components with 25 negative $\mu^{182} \mathrm{~W}$ and high ${ }^{3} \mathrm{He} /{ }^{4} \mathrm{He}$. Recent work measuring sulfur isotopes in ocean island 26 basalts has established that recycled oceanic and continental crust host unique S-isotope 27 compositions that can be identified at various hotspot localities. Here we document 28 previously unknown relationships between $\Delta^{33} S$ and radiogenic tungsten, helium and 29 lead isotopes from 7 Samoan basalts (from the islands of Ofu, Vailulu'u and Malumalu) that 30 suggest mixing between several endmembers. One, a HIMU influence that has slight 31 positive $\Delta^{33} S$ and positive $\delta^{34} S$; another, related to EM II that has near zero $\Delta^{33 S}$ and 32 positive $\delta^{34} S$; a third, which is primordial with negative $\mu^{182} \mathrm{~W}$, high ${ }^{3} \mathrm{He} /{ }^{4} \mathrm{He}$, that 33 has $\Delta^{33} \mathrm{~S}=0$ and negative $\delta^{34} \mathrm{~S}$. From this, we conclude that the indistinguishable $\Delta^{33} \mathrm{~S}$ of the 34 primordial endmember from that of the convective mantle indicates that sulfur isotopes 35 were homogenized early in Earth's history. The Vailulu'u sample with HIMU characteristics, 36 carries a small but resolvable $\Delta^{33} \mathrm{~S}$ that allows, but does not require mass-independent 37 Archean $\Delta^{33} S$ to shift the $\Delta^{33}$ S. The observed correlations involving $\Delta^{33} S$ supports 38 arguments linking $\mathrm{Pb}, \mathrm{He}$, and $\mathrm{W}$ geochemistry to a deep mantle process and places 39 constraints on questions related to the sources of mantle geochemical heterogeneity. 


\section{Introduction}

Basalts erupted at ocean islands (OIBs) are thought to sample both the deep and convective mantle, and provide insight into the diversity of mantle reservoirs. Long-lived radiogenic isotope compositions of strontium $(\mathrm{Sr})$, neodymium $(\mathrm{Nd})$, and lead $(\mathrm{Pb})$ from OIBs reveal compositional heterogeneity of the mantle and have formed the basis for identifying distinct mantle reservoirs produced by melt removal and incorporation of recycled components over time (Zindler and Hart 1986). The process of core formation and further planetary differentiation allowed for the production of an early formed reservoir (from here forward in this paper, we refer to this as a primordial reservoir). Components of this reservoir are observed in modern mantle plume basalts such as Samoa, and are manifested as isotopic anomalies in the short lived radiogenic isotope composition of tungsten (W) (Mundl-Petermeier et al., 2019; Mundl et al., 2017; Rizo et al., 2016; also see Kruijer and Kleine, 2018) and noble gas signatures of helium (He), neon (Ne), xenon (Xe), and argon (Ar) (e.g. Kurz et al., 2009; Mukhopadhyay, 2012). The isotopic observations that identify primordial components in mantle plume systems have suggested links to Large Low Shear Velocity Provinces (LLSVPs) and Ultra Low Velocity Zones (ULVZs) in the deep mantle (Williams et al., 2019).

Here, we present new bulk rock quadruple sulfur isotope data on $(n=7)$ basalts from three Samoan volcanoes--Ofu, Vailulu'u and Malumalu (figure 1)--to explore whether sulfur isotopes provide insight into the primordial signatures described above. So far sulfur isotopes have been used to track recycling of exogenic sulfur into plume systems (Cabral et al., 2013; Delavault et al., 2016; Labidi et al., 2015), to identify an isotopic imprint of planetary differentiation (Labidi et al., 2013), and to trace magmatic processes such as 
degassing (Beaudry et al., 2018). The observation of mass-independent $\left(\Delta^{33} S \neq 0\right)$ and mass-dependent $\left(\Delta^{33} S=0\right.$, variable $\left.\delta^{34} S\right)$ signatures of sulfur in mantle samples highlights its potential value for study in other mantle systems. The samples studied here yield a relationship between $\mu^{182} \mathrm{~W}$ and ${ }^{3} \mathrm{He} /{ }^{4} \mathrm{He}$ that illustrate a contribution from a primordial component (negative $\mu^{182} \mathrm{~W}$ anomalies associated with high ${ }^{3} \mathrm{He} /{ }^{4} \mathrm{He}$ ) and a non-primordial component. This offers an opportunity to place constraints on the primordial sulfur isotope composition of the mantle and to offer insight into the source of non-primordial $\mathrm{W}$ and $\mathrm{He}$ isotope compositions.

\section{Geologic Context/Background}

\subsection{Samoan radiogenic isotopic geochemistry}

Samoa is historically seen as sampling the archetypical Enriched Mantle-II (EMII) mantle source (e.g. Zindler and Hart, 1986). More recent work on radiogenic isotope signatures of lead $(\mathrm{Pb})$ argues that the various Samoan volcanoes receive contributions from multiple mantle endmember sources (Jackson et al. 2014a) including a depleted component, recycled components, and a primordial component, and these are sampled in the Vai, Malu, and Upo volcanic lineaments. Radiogenic isotopic compositions of strontium $(\mathrm{Sr})$, neodymium $(\mathrm{Nd})$, and lead $(\mathrm{Pb})$ for samples from Samoa reveal signatures of recycled, subducted oceanic and continental crust in endmembers such as: the Enriched Mantle 1 (EMI) component in rejuvenated Samoan lavas, the Enriched Mantle 2 (EMII) component at 
Malumalu seamount and Savai'i submarine lavas, and the dilute HIMU (high $\mu={ }^{238} \mathrm{U} /{ }^{204} \mathrm{~Pb}$ ) component at Ta'u island and Vailulu'u seamount (Jackson et al., 2014; Workman et al., 2004). The EMI endmember is characterized by relatively low ${ }^{143} \mathrm{Nd} /{ }^{144} \mathrm{Nd}$ and ${ }^{206} \mathrm{~Pb} /{ }^{204} \mathrm{~Pb}$ at high ${ }^{87} \mathrm{Sr} /{ }^{86} \mathrm{Sr}$, and high ${ }^{208} \mathrm{~Pb} /{ }^{204} \mathrm{~Pb}$ at a given ${ }^{206} \mathrm{~Pb} /{ }^{204} \mathrm{~Pb}$. The EMII source is characterized by the highest ${ }^{87} \mathrm{Sr} /{ }^{86} \mathrm{Sr}$ and ${ }^{208} \mathrm{~Pb} /{ }^{204} \mathrm{~Pb}$ at a given ${ }^{206} \mathrm{~Pb} /{ }^{204} \mathrm{~Pb}$ and its origin is argued to reflect the subduction and recycling of continental sediments (Jackson et al., 2007a; Workman et al., 2008). The HIMU endmember is thought to reflect recycled oceanic crust after it experienced $\mathrm{Pb}$ loss during subduction, hence leading to ingrowth of radiogenic ${ }^{206} \mathrm{~Pb} /{ }^{204} \mathrm{~Pb}$ (e.g. Kelley et al., 2005 and references within) .

Studies of ocean island basalts, including Samoa, also suggest various ocean islands host primordial mantle components. Evidence for this comes from high ${ }^{3} \mathrm{He} /{ }^{4} \mathrm{He}$ ratios in Hawaii (e.g. Kurz et al., 1983, Valbracht et al., 1997 and references within), Samoa (Jackson et al., 2009, 2007b), Iceland (e.g. Macpherson et al., 2005 and references within), Galapagos (Graham et al., 1993; Kurz et al., 2009), and Baffin Island (Starkey et al., 2009; Stuart et al., 2003). Additional evidence for early-formed "primordial" mantle domains is observed through the association of primitive Ar and $\mathrm{Ne}$, and ancient Xe isotope signatures in mantle plumes with high ${ }^{3} \mathrm{He} /{ }^{4} \mathrm{He}$ (e.g. Kurz et al., 2009; Mukhopadhyay, 2012), negative $\mu^{182} \mathrm{~W}$ compositions associated with high ${ }^{3} \mathrm{He} /{ }^{4} \mathrm{He}$ in Samoa and Hawaii (Mundl et al., 2017), and positive $\mu^{182} \mathrm{~W}$ in Baffin island and Ontong Java Plateau (Rizo et al., 2016; also see Kruijer and Kleine, 2018).

\subsection{Unique seismic structures beneath Samoa}


110 for compositional heterogeneity in the deep mantle has been mounting. Recent studies

111 confirm that at the largest scales, the pair of Large low Shear Velocity Province (LLSVPs)

112 appear to be associated with both low shear wavespeed and high density, a telltale 113 signature of compositional heterogeneity (Lau et al., 2017; Moulik and Ekström, 2016). At 114 smaller scales, Ultra Low Velocity Zones (ULVZs), whose properties have been interpreted 115 to represent either partial melt (Williams and Garnero, 1996) or very high iron enrichment

116 (Wicks et al., 2010), have now been detected beneath Samoa (Thorne et al., 2013), Hawaii 117 (Cottaar and Romanowicz, 2012), and Iceland (Yuan and Romanowicz, 2017). High 118 resolution global tomographic models constructed using full waveform inversion have 119 been interpreted to require the presence of compositional heterogeneity within plume 120 conduits themselves (French and Romanowicz, 2015). Importantly, efforts in mantle 121 geochemistry have begun to associate mantle reservoirs that host primordial components, 122 such as that sampled by Samoa, to Large Low shear Velocity Provinces (e.g. Williams et al., 123 2019) and Ultra Low Velocity Zones (e.g. Mundl et al., 2017) that reside at the base of the 124 mantle. These observations continue to contribute evidence that mantle plumes are 125 sampling reservoirs that are both deep and compositionally distinct from the ambient 126 mantle.

\section{Methods}

Splits (1 to 3 gram aliquots) of the same fine crushed powder from Mundl et al. 130 (2017) were placed into Teflon reactors for acid digestion as described by Labidi et al. 
131 (2012). These samples are a different type from those studied by Labidi et al. (2015) in that 132 the samples are not glasses but, are rather the same powder from the interiors of the 133 sampled flows used by Mundl. et al (2017). Prior to digestion, the setup was degassed with $134 \mathrm{~N}_{2}$ for $\sim 15$ minutes. After degassing, the samples were acidified and digested in heated $135\left(70-80^{\circ} \mathrm{C}\right) 3.2 \mathrm{M} \mathrm{CrCl}_{2}, 12 \mathrm{M} \mathrm{HCl}$, and $29 \mathrm{M} \mathrm{HF}$ in the amounts of $10 \mathrm{ml}, 5 \mathrm{ml}$, and $5 \mathrm{ml}$ 136 respectively. The amount of solution was doubled for larger samples ( $>2$ grams of powder). 137 Sulfides were released as $\mathrm{H}_{2} \mathrm{~S}$ that is then bubbled (pulsed bubbling of $\sim 3-5$ bubbles every $138 \sim 1-2$ seconds) through a water trap and lastly trapped as $\mathrm{Ag}_{2} \mathrm{~S}$ in an acidic $\mathrm{AgNO}_{3}$ trap 139 solution. The captured $\mathrm{Ag}_{2} \mathrm{~S}$ subsequently transferred to a $1.5 \mathrm{ml}$ Eppendorf centrifuge tube 140 where it was then rinsed, agitated with a vortex machine for 10 seconds, and centrifuged 141 with Milli-Q water. The supernatant was pipetted off and the rinsing procedure was 142 repeated 6 times. After rinsing, the $\mathrm{Ag}_{2} \mathrm{~S}$ was dried at $70{ }^{\circ} \mathrm{C}$. The dried $\mathrm{Ag}_{2} \mathrm{~S}$ was then 143 weighed to determine sulfur concentration and the $\mathrm{Ag}_{2} \mathrm{~S}(0.3 \mathrm{mg}$ to $5 \mathrm{mg}$ ) reacted with 3-5 144 times excess $\mathrm{F}_{2}$ in heated $\left(\sim 250^{\circ} \mathrm{C}\right)$ nickel reaction tubes for at least 8 hours. Note, some 145 samples yielded greater than $5 \mathrm{mg}$ of $\mathrm{Ag}_{2} \mathrm{~S}$ (up to $15 \mathrm{mg}$ ). For these samples, 3-5mg splits 146 were taken and used for isotopic analyses. The resulting $\mathrm{SF}_{6}$ was transferred to a liquid 147 nitrogen cooled trap and the residual $\mathrm{F}_{2}$ was passivated by a reaction with $\sim 110^{\circ} \mathrm{C} \mathrm{KBr}$ 148 salt. After passivation, the liquid nitrogen trap was replaced by an ethanol slush $\left(\sim-108^{\circ} \mathrm{C}\right.$ 149 to $-115^{\circ} \mathrm{C}$ ) in an effort to separate $\mathrm{HF}$ from the remaining $\mathrm{SF}_{6}$. Once separated, the $\mathrm{SF}_{6}$ was 150 transferred to a liquid nitrogen cooled injection loop of a gas chromatograph (GC). Next, the $151 \mathrm{SF}_{6}$ was simultaneously thawed and injected into the gas chromatograph with flowing 152 helium at a rate of $20 \mathrm{~mL} / \mathrm{min}$. The gas chromatograph allows for a final $\mathrm{SF}_{6}$ purification 153 using a 1/8-inch diameter, 20-foot long Haysep-Q ${ }^{\mathrm{TM}}$ GC column. The $\mathrm{SF}_{6}$ was monitored 
154 while passing through the (GC) and captured from the helium flow in liquid nitrogen cooled 155 spiral metal tubes. Lastly, the captured purified $\mathrm{SF}_{6}$ was measured manometrically to 156 determine procedural yields and preserved in individual sample fingers of glass manifolds. 157 Yields determined from fluorination range from $70 \%$ to $106 \%$. The glass manifold was then 158 attached to an additional liquid nitrogen cooled manifold that is used to introduce SF $_{6}$ into 159 the sample bellows of a Thermo Finnigan MAT 253 dual-inlet mass spectrometer.

\subsection{Mass Spectrometry}

Sulfur has four stable isotopes $\left({ }^{32} \mathrm{~S}(95.2 \%),{ }^{33} \mathrm{~S}(0.75 \%),{ }^{34} \mathrm{~S}(4.25 \%)\right.$, and ${ }^{36} \mathrm{~S}$ 162 $(0.02 \%))$, and isotopic variations of sulfur isotopes were determined using mass spectrometry of purified $\mathrm{SF}_{6}$. The purified $\mathrm{SF}_{6}$ was measured by monitoring $\mathrm{SF}_{5}{ }^{+}$ion beams at $\mathrm{m} / \mathrm{z}$ of $127,128,129$, and 131 . Data are reported in per mil using the following notation:

$$
\delta^{33} \mathrm{~S}=\left[\left(\left({ }^{33} \mathrm{~S} /{ }^{32} \mathrm{~S}\right)_{\text {sample }} /\left({ }^{33} \mathrm{~S} /{ }^{32} \mathrm{~S}\right)_{\mathrm{CDT}}\right)-1\right]
$$

$$
\delta^{34} \mathrm{~S}=\left[\left(\left({ }^{34} \mathrm{~S} /{ }^{32} \mathrm{~S}\right)_{\text {sample }} /\left({ }^{34} \mathrm{~S} /{ }^{32} \mathrm{~S}\right){ }_{\mathrm{CDT}}\right)-1\right]
$$

$$
\delta^{36} \mathrm{~S}=\left[\left(\left({ }^{36} \mathrm{~S} /{ }^{32} \mathrm{~S}\right)_{\text {sample }} /\left({ }^{36} \mathrm{~S} /{ }^{32} \mathrm{~S}\right)_{\mathrm{CDT}}\right)-1\right]
$$

171 All analyses were normalized to analyses of a large, single reservoir of $\mathrm{SF}_{6}$ gas produced by 172 fluorination of IAEA-S1 undertaken in the same session as the sample analyses. This 173 normalization was conducted during each analytical session to account for changes in the 
composition of different aliquots of mass spectrometer reference gas. We developed this approach for studies of meteorite samples and found that the approach yields more accurate and reproducible $\Delta^{33}$ S (Antonelli et al., 2014). The data are then normalized to the value measured for Canyon Diablo Troilite (CDT) using the same approach and calibration in Antonelli et al. (2014) and Dottin et al. (2018). This places IAEA-S1 at a value of $\delta^{33} \mathrm{~S}=-$ $0.091 \%, \delta^{34} \mathrm{~S}=-0.401 \%, \delta^{36} \mathrm{~S}=-1.558 \%, \Delta^{33} \mathrm{~S}=0.116 \%$, $\Delta^{36} \mathrm{~S}=-0.796 \%$.

Estimates of uncertainty can be assigned on the basis of measured long-term reproducibility of independent fluorinations of a variety of reference materials. These uncertainties include contributions from mass spectrometry and chemical preparation and, for $\Delta^{33} \mathrm{~S}$, vary depending on the mass spectrometry counting times. For $\delta^{34} \mathrm{~S}$ and $\Delta^{36} \mathrm{~S}$ the long-term reproducibility on reference materials is $\pm 0.3 \%$ and $\pm 0.3 \% 0(2 \sigma)$. For $\Delta^{33} \mathrm{~S}$, the long-term reproducibility is $\pm 0.008 \%$, and $\pm 0.016 \%$ o $(2 \sigma)$, for mass spectrometry analyses made using 9 and 3 analytical cycles, respectively.

The reproducibility reported in Table 1 of 2 (SE) represents the in-run precision from mass spectrometry and renormalization determined by Monte Carlo error propagation. The reproducibility (SE) for $\delta^{34} S$ and $\Delta^{36} S$ is smaller than seen from the longterm reproducibility on IAEA-S1 due to factors associated with the chemical procedures in preparing the $\mathrm{SF}_{6}\left(\delta^{34} \mathrm{~S}\right)$ and interferences $\left(\Delta^{36} \mathrm{~S}\right)$. The reproducibility (SE) is comparable to that seen for $\Delta^{33} S$ on the basis of long-term reproducibility on IAEA-S1. This suggests greatest contributor to reproducibility for $\Delta^{33}$ comes from mass spectrometry. Estimates of precision (total uncertainty) are assumed to be the larger of the long-term reproducibility of reference materials and the propagated, normalized mass spectrometry 
196

data. These are presented in Table 1. For figures we plot estimated uncertainty. We use a Bayesian approach (details given in supplementary information) to assess match between data and models for relationships between sulfur isotope data and other geochemical systems.

\section{Results}

Data from 7 Samoan basalts are presented in table 1 and figure 2. Sulfur concentrations of the bulk rock phase represent a lower limit, as a small amount of S could be lost in the sample preparation (rinsing and weighing procedure). Concentrations range from $30 \mathrm{ppm}$ to $800 \mathrm{ppm} \mathrm{S}$ and isotopic compositions extend from +1.08 to $+4.23 \%$ o \pm $0.3),-0.004$ to $+0.027 \%$ o $( \pm 0.008)$, and -0.29 to $+0.22 \%$ o $( \pm 0.3)$ in $\delta^{34} S, \Delta^{33} S$, and $\Delta^{36} \mathrm{~S}$ respectively. With the exception of sample Ofu-04-15 $\left(\delta^{34} S=+4.23 \%\right)$, the $\delta^{34} S$ data are within the range of compositions previously reported $(+0.11 \%$ to $+2.79 \%$, Labidi et al., 2015). The $\Delta^{33} S$ and $\Delta^{36} S$ are all within the previously reported range, $+0.001 \%$ to $+0.022 \%$, and $-0.063 \%$ o to $+0.271 \%$, for $\Delta^{33} \mathrm{~S}$ and $\Delta^{36} \mathrm{~S}$ respectively ${ }^{1}$. The compositions we observe are within the range of bulk sulfur isotope compositions reported for the global dataset of glasses from ocean island and mid ocean ridge basalts where values range from $\sim-3 \%$ to $+3 \%$ in $\delta^{34}$ S and $-0.01 \%$ to $+0.01 \%$ in $\Delta^{33}$ S (Labidi et al., $2015,2014,2013$ ). However, the observed compositions are not as extreme as the isotopic data obtained on individual sulfides via secondary ion mass spectrometry (SIMS), at localities such as the

\footnotetext{
${ }^{1}$ The compositions reported here are not shifted to the CDT scale in $\delta^{34} \mathrm{~S}$ and the UMD-CDT scale for $\Delta^{33} \mathrm{~S}$. This shift in normalization yields a $-0.1 \%$ shift in $\delta^{34} \mathrm{~S}$ and a $+0.01 \%$ o shift in $\Delta^{33} \mathrm{~S}$ which would convert to +0.01 to $+2.69,+0.011$ to +0.032 , and -0.063 to +0.271 for in $\delta^{34} S, \Delta^{33} S$, and $\Delta^{36} \mathrm{~S}$ respectively.
} 
216 Canary Islands that reveal large negative $\delta^{34} S$ variations (up to $-8.2 \% 0$ ) assigned to 217 degassing with strictly mass dependent $\Delta^{33} S$ (Beaudry et al., 2018) and Mangaia and 218 Pitcairn that show large negative $\delta^{34}$ S variations $(-17.25 \%$ to $-2.25 \%$ ) associated with 219 sub-permil $\Delta^{33}$ S variations (0 to $-0.85 \%$ ) (Cabral et al., 2013; Delavault et al., 2016). These 220 SIMS measurements resolve isotopic difference on a granular scale, which is different from 221 bulk measurements presented here, and have larger uncertainties.

Our data reveal relationships between $\Delta^{33} \mathrm{~S}$ and radiogenic isotopic compositions of $\mathrm{W}, \mathrm{Pb}$, and He. The data do not, however, preserve a relationship between $\delta^{34} \mathrm{~S}$ and

224 radiogenic isotopic compositions of $\mathrm{W}, \mathrm{Pb}$, and $\mathrm{He}$. In order to assess the significance of 225 these relationships, we employed a Bayesian model selection approach to quantify the 226 relative probability that the underlying relationship is represented by a line (M1) versus a 227 constant value (i.e. line with zero slope; M2). We explicitly marginalize out the extra 228 tunable parameter (slope of the line) present in M1, and assume that the errors in both 229 composition estimates are normally distributed and uncorrelated. We find that the 230 radiogenic $\mathrm{W}, \mathrm{Pb}$, and He vs. $\Delta^{33} \mathrm{~S}$ data strongly prefer $\mathrm{M} 1$ over $\mathrm{M} 2$ (> 99\% chance of being 231 true).

\section{5. Discussion}

We report sulfur concentrations in the interior of pillow basalts erupted at Ofu, 235 Vailulu'u and Malumalu that range from 30 to $800 \mathrm{ppm}$. These are lower than 236 concentrations seen in glasses erupted at these islands (600 to $2000 \mathrm{ppm} \mathrm{S}$, Labidi et al. 237 2015). Typically, samples of glass, erupted at ocean depths greater than 1000 meters have 
the greatest chance of preserving the sulfur concentrations and isotopic compositions of 239 the erupted melt (Moore and Fabbi, 1971). The bulk rock samples from Vailulu'u and 240 Malumalu are from submarine eruptions (they were collected at water depths of $\geqslant 92$ bars) 241 and preserve slightly higher sulfur concentrations, but are at the low end (600-800 ppm) of 242 the S concentrations reported for samples of glass from the same localities by Workman et 243 al. (2006) and Labidi et al. (2015) and in some cases (see table 1, supplementary figure 2) 244 reveal even lower concentrations $(\sim 200 \mathrm{ppm})$ than the lowest value $(\sim 600 \mathrm{ppm})$ reported 245 by Labidi et al., (2015). Bulk rock samples with the lowest S concentrations (30 and 60 ppm 246 S) are subaerial lavas from Ofu. Sulfur loss can also be associated with isotopic shifts in $247 \quad \delta^{34} \mathrm{~S}$, but not $\Delta^{33} \mathrm{~S}$ or $\Delta^{36} \mathrm{~S}$.

The sulfur isotope compositions of Samoan basalts (from this study and Labidi et al., 2492015 ) are ${ }^{34}$ S-enriched relative to the composition of mantle sulfur proposed by Labidi et 250 al. $(2013,2014)$ of $-1 \pm 0.5 \%$. These ${ }^{34}$ S-enrichments could be caused by recycling of ${ }^{34} \mathrm{~S}$ 251 bearing subducted components (Labidi et al. 2015), or by syn-eruptive or post-eruptive 252 sulfur loss. While sulfur loss could be accounted for by episodes of sulfide segregation, as 253 seen in some Samoan melts (Labidi et al. 2015), we argue that the lowest sulfur 254 concentrations observed here illustrate sulfur loss through an event(s) of sulfur degassing 255 and that the loss of sulfur $\left({ }^{32} \mathrm{~S}\right)$ could account for the increasing ${ }^{34} \mathrm{~S}$-enriched characteristic 256 of the Ofu samples $\left(\delta^{34} \mathrm{~S}=+1.8 \%\right.$ and $\left.+4.3 \% 0\right)$. A similar shift in $\delta^{34} \mathrm{~S}$ from degassing cannot 257 be ruled out for the samples from Vailulu'u and Malumalu, however, some of these samples 258 still overlap the range of sulfur isotopic compositions seen for Samoan glasses by Labidi et 259 al. (2015) (Figure 2). 
261 fractionation, or a combination of both. At the Quartz-Fayalite-Magnetite reaction buffer, $262 \mathrm{SO}_{2}$ dominates the gas phase (Burgisser et al., 2015; Gaillard and Scaillet, 2009), and 263 degassing is expected for melts erupting at less than 100 bars pressure ( 1000 m depth ) 264 (Gaillard and Scaillet, 2009). At 1200 degrees C, sulfur dioxide is ${ }^{34}$ S-enriched by $\sim 1.5$ to $2653 \%$ relative to the dissolved sulfide in the melt (e.g. Mandeville et al., 2009), and 266 equilibrium degassing of sulfur dioxide drives the melt to more negative $\delta^{34} \mathrm{~S}$ compositions. 267 If instead the $\mathrm{S}$ were degassed as $\mathrm{H}_{2} \mathrm{~S}, \mathrm{~S}$ loss would result in a negligible fractionation of ${ }^{34} \mathrm{~S}$ 268 (Mandeville et al., 2009) but $\mathrm{H}_{2} \mathrm{~S}$ loss is not supported by degassing models of melts with 269 these compositions and oxygen fugacities (Burgisser et al., 2015). The alternative, kinetic 270 degassing, results upon rapid loss of $\mathrm{S}$ and generates a ${ }^{34} \mathrm{~S}$ heavy residual melt, rather than 271 depletion, driving the melt towards positive $\delta^{34}$ S (e.g. de Moor et al., 2013 and references 272 within). Note, positive $\delta^{34}$ S can be achieved during decompression degassing in highly 273 oxidizing conditions ( $>$ QFM +3 , Fiege et al., 2014). Degassing almost certainly occurred, 274 however our data do not allow for a single process with a singular fractionation to be 275 identified (supplementary figure 1). This limits our ability to project back to the $\delta^{34} \mathrm{~S}$ of an 276 initial magma. We note that oxidative weathering of the crystalline interiors may have 277 induced the loss of reduced S. Studies of isotope effects associated with low temperature 278 oxidation by Heidel et al. (2013) show no change in the $\delta^{34} \mathrm{~S}$ of the residual sulfides from 279 oxidation, but, reveal a fractionation for the product sulfate which they attribute to 280 formation of more than one product. Thus, in the event of oxidative weathering, it is 281 expected that the $\delta^{34}$ S of sulfide would still reflect that of its parental melt. 

higher $\mathrm{S}$ concentrations than the analyzed Ofu samples and we suggest (see above) that sulfur degassing may have only minimally modified the isotopic composition. These samples have $\delta^{34}$ S compositions $(+1.23$ to $+2.30 \%$ ) that fall within the range of values previously reported on glassy Samoan basalts by Labidi et al., (2015) and exhibit similar radiogenic isotope compositions for $\mathrm{Pb}, \mathrm{Sr}$, and $\mathrm{He}$ (Figure 3). Even though the sulfur concentrations are generally lower than that observed by Labidi et al., (2015) 290 (supplementary figure 2), the geochemical similarity between the samples suggests they 291 are part of the same population. Thus, we defer to the study by Labidi et al. (2015) for 292 insight into the $\delta^{34}$ S of the primary magma, where they identified a mixing array between a 293 lower ${ }^{87} \mathrm{Sr} /{ }^{86} \mathrm{Sr}$ mantle domain with negative $\delta^{34} \mathrm{~S}$, and an EMII endmember with positive $294 \delta^{34}$ S.

The relationship between $\Delta^{33} \mathrm{~S}$ and other geochemical systems such as tungsten, 296 helium and lead isotopes reflects mixing of mantle reservoirs sampled by the Samoa mantle 297 plume, including a recycled component with dilute HIMU characteristics (Jackson et al., 298 2014), an EMII sulfur component that has been documented by Labidi et al. (2015) and a 299 primordial endmember defined by negative $\mu^{182} \mathrm{~W}$ and high ${ }^{3} \mathrm{He} /{ }^{4} \mathrm{He}$ (Mundl et al., 2017). 300 Below, we explore in greater detail various scenarios for interpreting the relationships 301 between sulfur and other geochemical systems. We start by discussing the connection with 302 the recycled component and then discuss the connection with the primordial endmember 303 in the context of its suggested origin and placement this endmember. 
305 (figure 4) and also the same field for $\delta^{34} S$ vs $\Delta^{33} S$ (figure 2) as defined for volcanic glasses 306 of the Samoan volcanic chain reported by Labidi et al. (2015). Labidi et al. (2015) argue 307 that these relationships between $\delta^{34} \mathrm{~S}$ and ${ }^{87} \mathrm{Sr} /{ }^{86} \mathrm{Sr}$ reflect mixing between an EMII mantle 308 endmember with positive $\delta^{34} \mathrm{~S}(+10 \pm 3 \% 0)$ and radiogenic ${ }^{87} \mathrm{Sr} /{ }^{86} \mathrm{Sr}$ and a mantle domain 309 with negative $\delta^{34} \mathrm{~S}_{\mathrm{V}-\mathrm{CDT}}(-0.89 \pm 0.11(1 \sigma))$ and less radiogenic ${ }^{87} \mathrm{Sr} /{ }^{86} \mathrm{Sr}$. Minor scatter in 310 the $\Delta^{33} \mathrm{~S}$ of the combined data allows for other components with different $\Delta^{33} \mathrm{~S}$, such as 311 HIMU, as underplating of HIMU-enriched material to the crust below Samoa has been 312 proposed as the outcome of the earlier passage of the Cook-Austral plumes (Workman et 313 al., 2004); however, the HIMU component may also be indigenous to the Samoan plume 314 (Jackson et al., 2014). Jackson et al. (2014) argue that the Vailulu'u lavas reveal 315 characteristics suggestive of a dilute HIMU signature. The slightly elevated $\Delta^{33} \mathrm{~S}$ in Vailulu'u 316 lavas is interpreted to reflect a dilute contribution from a HIMU component that possess 317 variable anomalous $\Delta^{33}$ S. A similar observation is observed in lavas from Vailulu'u in Labidi 318 et al. (2015). Given the data from Malumalu (EM2) and Vailulu'u (dilute HIMU) occupy 319 different fields for $\delta^{34} \mathrm{~S}$ and ${ }^{87} \mathrm{Sr} /{ }^{86} \mathrm{Sr}$ and a slightly different field for $\delta^{34} \mathrm{~S}$ vs $\Delta^{33} \mathrm{~S}$ (figure 2 ), 320 the case may be that the sources of sulfur are indeed different for the Vai and Malu volcanic 321 lineament. The high ${ }^{87} \mathrm{Sr} /{ }^{86} \mathrm{Sr}$ in EM2 Malumalu lavas (and possibly the Vailulu'u lavas, 322 which also have moderately elevated ${ }^{87} \mathrm{Sr} /{ }^{86} \mathrm{Sr}$ ), combined with observed $\delta^{34} \mathrm{~S}$ vs $\Delta^{33} \mathrm{~S}$, 323 allows for a potential mixture of both Proterozoic and Archean sediments (Labidi et al., 324 2015). In this type of mixture, the small magnitude $\Delta^{33} S$ signature could also be contributed 325 by Proterozoic sediments (See Johnston (2011) for data compilations showing such 326 characteristics for early to middle Proterozoic sediments). Such small-magnitude positive 
and negative shifts of $\Delta^{33} \mathrm{~S}$ are a natural outcome of biological and biogeochemical cycling (Ono et al., 2006) and are seen in sulfide and sulfate from a wide range of sedimentary and hydrothermal systems (Johnston, 2011).

\subsection{Sulfur from the primordial mantle}

The plume component with which this recycled endmember is mixed hosts a heterogeneous radiogenic $\mathrm{Pb}$ isotopic composition. The data from Samoa define four arrays in ${ }^{206} \mathrm{~Pb} /{ }^{204} \mathrm{~Pb}$ vs. ${ }^{204} \mathrm{~Pb} /{ }^{204} \mathrm{~Pb}$ that all converge on a small range of values $(19.0-19.3$ in ${ }^{206} \mathrm{~Pb} /{ }^{204} \mathrm{~Pb}, 39.0-39.4$ in ${ }^{208} \mathrm{~Pb} /{ }^{204} \mathrm{~Pb}$ ) (Jackson et al., 2014) that are associated with the high ${ }^{3} \mathrm{He} /{ }^{4} \mathrm{He}$ ratios of the "common component" (20-33.8 $\left.\mathrm{R}_{\mathrm{A}}\right)$. Samples from Samoa with high ${ }^{3} \mathrm{He} /{ }^{4} \mathrm{He}$ also preserve negative $\mu^{182} \mathrm{~W}$ compositions (Mundl et al., 2017). Such ${ }^{182} \mathrm{~W}$ deficits require a separate evolution from mantle-hosted ${ }^{182} \mathrm{Hf}$, which went extinct within the first 60 million years of solar system history. ${ }^{182} \mathrm{~W}$ deficits are thus signatures formed early in Earth's accretionary history that were immediately isolated from mantle convection and mixing (Mundl et al., 2017).

The observed relationships between $\mathrm{S}$ with $\mathrm{He}$ and $\mathrm{W}$ (figure 3) suggests the contribution of sulfur from an undegassed, early-formed mantle reservoir. Our data establish that materials linked to the deep primordial component have $\Delta^{33} \mathrm{~S} \approx 0 \%$, similar to the average MORB value of $0.008 \pm 0.006 \%$ ( $n=80,1$ s.d., Labidi and Cartigny 2016). A homogeneous mantle $\Delta^{33} \mathrm{~S}$ with variable $\mu^{182} \mathrm{~W}$ supports a process that homogenized $\Delta^{33} \mathrm{~S}$ prior to the ingrowth of $\mu^{182} \mathrm{~W}$ signatures in different reservoirs. In Samoan lavas, the recycled components bring materials with $\Delta^{33} \mathrm{~S} \neq 0 \%$ associated with the recycled component with HIMU characteristics (Jackson et al., 2014) and the observed relationship 
is apparent because this component has a different $\Delta^{33} S$ than the endmember with 350 negative $\mu^{182} \mathrm{~W}$. It was shown that the convective mantle is defined by $\Delta^{33} \mathrm{~S}$ and $\mu^{182} \mathrm{~W}$ both 351 equal to zero (e.g. Labidi et al., 2014; Willbold et al., 2011). We therefore expect future 352 analyses will fill in a three-component mixing field for $\Delta^{33} S$ and $\mu^{182} \mathrm{~W}$ (though, hints of this 353 field may already be present in figure 5); endmember 1 is a primordial component, 354 endmember 2 is a recycled component, endmember 3 is the convecting mantle.

To allow for an early segregated metal-rich reservoir with a ${ }^{182} \mathrm{~W}$ deficit, Mundl et al.

(2017) suggest a connection to deep mantle reservoirs such as the seismically-defined Large Low Shear Velocity Province (LLSVP) or Ultra Low Velocity Zone (ULVZ) beneath Samoa which have been suggested to host Fe-rich metals (e.g. Zhang et al., 2016) and/or may have interacted with the core (Rizo et al., 2019). Work by Frost et al. (2004) suggests the formation of such metal could have occurred via an $\mathrm{Fe}^{2+}$ disproportionation pathway driven by formation of bridgmanite early in Earth's history. This process has the potential to yield a reservoir of deep mantle metal with moderate $\mathrm{W}$ abundances and low HSEs (Mundl et al., 2017). Zhang et al. (2016) point out that S will concentrate in this metal phase, which in turn will mute the expression of the equilibrium metal/silicate fractionation (>1\%o: Labidi et al., 2016) and yield an isotopic composition similar to that of the mantle in which it formed (negative $\delta^{34} S$ and $\Delta^{33} S=0 \% 0$ ). This composition is consistent with the composition of sulfur we infer for the endmember with negative $\mu^{182} \mathrm{~W}$.

An alternative proposed mechanism for producing negative $\mu^{182} \mathrm{~W}$ variations involve high-pressure episodes of core formation that are recorded and preserved in the deep mantle (Jackson et al. 2018). At high pressure, sulfur remains a siderophile element 
371 (Suer et al. 2017) but the isotopic effect remains unconstrained. There is a potential for 372 changes in the mass dependent fractionation of ${ }^{34} \mathrm{~S} /{ }^{32} \mathrm{~S}$ (see discussion in Labidi et al. 373 2016), but we consider it unlikely that the $\Delta^{33} S$ would be affected in the formation of the 374 deep mantle reservoir.

Mundl et al., (2017) discount the possibility that physical core metal entrainment was the source of primordial (negative) $\mu^{182} \mathrm{~W}$ because HSEs are not sufficiently enriched in Samoan lavas and are uncorrelated with negative $\mu^{182} \mathrm{~W}$. In consideration of the mantle nature of sulfur in samples with increasingly negative $\mu^{182} \mathrm{~W}$ from Vailulu'u and Malumalu ${ }^{2}$, the data suggest the primordial component likely has negative $\delta^{34} \mathrm{~S}$, which would be inconsistent with the core being the source of the sulfur that was later diluted with recycled sediments. Labidi et al. (2013) and Labidi and Cartigny (2016) argue that the $\delta^{34} \mathrm{~S}$ of the bulk Earth, if chondritic, must be between -0.27 and $+0.04 \%$. In this case, the mantle 383 and core bracket this value with the mantle having strongly negative $\delta^{34} S(-0.89 \pm 0.11 \%$ o (1б)) while the core is slightly ${ }^{34}$ S-enriched. Further support for the Mundl et al. (2017) suggestion that the $\mu^{182} \mathrm{~W}$ anomalies did not originate from entrainment of core material, may be provided by the lack of significant curvature in the $\Delta^{33} S-\mu^{182} \mathrm{~W}$ array (Figure 5) and the prevalence of near zero or slightly positive $\Delta^{33} \mathrm{~S}$ for early solar system materials (Antonelli et al., 2014). Significant curvature would be expected if the mantle mixed with core material to generate the $\Delta^{33} S-\mu^{182} \mathrm{~W}$ array (Figure 5) observed here, due to different $\mathrm{W} / \mathrm{S}$ ratios in the mantle and core. The lack of curvature also implies the W/S concentration ratio is not much different in the mixing endmembers and, unless the

${ }^{2}$ We set aside the data for two samples from Ofu because of the likelihood of late shifts of $\delta^{34} \mathrm{~S}$ from extreme degassing owing to shallow eruption of the Ofu lavas. 
392 primordial reservoir has negative $\Delta^{33} \mathrm{~S}$, the negative $\mu^{182} \mathrm{~W}$ endmember may not be 393 significantly more negative (e.g. if it was a direct core contribution) than the most negative 394 values that have been measured thus far.

More recent work by Mundl et al. (2019) introduce an argument for anomalous

$396 \mu^{182} \mathrm{~W}$ that involves a chemical and isotopic equilibration process for $\mathrm{W}$ between a basal

397 silicate layer and the core. Mundl et al. (2019) argue that the best candidate reservoirs are 398 seismically imaged ULVZs. An equilibration process that that generates a reservoir with $399 \mu^{182} \mathrm{~W}$ of $\sim-17$ for a $\Delta^{33} \mathrm{~S} \sim 0$ would explain our data (Mundl et al., 2020). The resulting 400 reservoir would mix with a recycled endmember with $\Delta^{33} S \neq 0$ to produce the arrays that 401 are seen. Using simple mixing calculations, the data are well fit with this model assuming 402 the amount of tungsten mixed into the basal silicate reservoir yields a $\mu^{182} \mathrm{~W}$ of $\sim-17$.

\section{Conclusions}

404 The Samoan islands are the type locality for the EM (II) reservoir but also receive dilute 405 contributions from EM (I), HIMU, and DMM related components. Furthermore, Samoa sits 406 above a seismically imaged LLSVP and ULVZ that is thought to be the source of material 407 that exhibit primordial isotope compositions, seen as high ${ }^{3} \mathrm{He} /{ }^{4} \mathrm{He}$ and negative $\mu^{182} \mathrm{~W}$. We 408 have characterized the nature of sulfur in primordial and recycled mantle sources using 409 multiple sulfur isotopes of bulk rock Samoan basalts by focusing on Samoan islands with 410 high ${ }^{3} \mathrm{He} /{ }^{4} \mathrm{He}$ and negative $\mu^{182} \mathrm{~W}$. Relationships between $\Delta^{33} \mathrm{~S}$ and other geochemical 411 systems such as radiogenic tungsten, helium and lead isotopes is observed and suggests 412 mixing between a component with HIMU characteristics (slight positive $\Delta^{33} S$ and 413 positive $\delta^{34} \mathrm{~S}$ ) with a primordial endmember (negative $\mu^{182} \mathrm{~W}$, high ${ }^{3} \mathrm{He} /{ }^{4} \mathrm{He}, \Delta^{33} \mathrm{~S}=0$ and 
414 negative $\delta^{34} \mathrm{~S}$ ). The antiquity of the primordial endmember is indicated by ${ }^{182} \mathrm{~W}$ deficits that 415 require a separate evolution from mantle-hosted ${ }^{182} \mathrm{Hf}$ within the first 60 million years of 416 solar system history. The similar indistinguishable $\Delta^{33} \mathrm{~S}$ from that of the convective mantle 417 indicates that sulfur isotopes were thus homogenized early in Earth's history. The small 418 but resolvable $\Delta^{33} S$ in the recycled endmember reflects sulfur that is contributed by a 419 Samoan plume component with HIMU characteristics (with a possible mixture of 420 Proterozoic sulfur from continental crust sediments). Although a contribution from mass421 independent Archean $\Delta^{33} \mathrm{~S}$ could be associated with HIMU, it is not required to explain the $422 \Delta^{33} \mathrm{~S}$ variation because younger (Proterozoic) contributions may also have small positive 423 and negative deviations from $\Delta^{33} \mathrm{~S}=0$. The correlations between sulfur, $\mathrm{Pb}, \mathrm{He}$, and $\mathrm{W}$ are 424 most easily reconciled with a deep mantle process linked to a dense, undegassed basal 425 reservoir such as a ULVZ. Although our data do not support a reservoir with $\mu^{182} \mathrm{~W}=-220$ 426 and $\Delta^{33} S=0$, the relationship between sulfur and tungsten could reflect $\mathrm{W}$ isotope 427 equilibration through a core-mantle equilibration process, where a diluted core $\mathrm{W}$ isotope 428 composition having less negative $\mu^{182} \mathrm{~W}$ is incorporated into the plume that also hosts 429 recycled sediments having $\Delta^{33} \mathrm{~S} \neq 0$. Ultimately, our work identifies relationships between 430 sulfur and radiogenic $\mathrm{Pb}, \mathrm{He}$, and $\mathrm{W}$ that provide a means of continuing to unravel the 431 complexities of geochemical heterogeneity of the mantle. With this work, we further the 432 understanding of how the subduction and recycling of oceanic and continental crust can 433 influence geochemical signatures observed at ocean islands and how well dispersed the 434 various reservoirs are in the mantle. 
437 providing useful comments. We also appreciate the thoughtful comments and suggestions

438 from three anonymous reviewers. This project was supported by the University of 439 Maryland Graduate School Research and Scholarship Award and a Fulbright Fellowship 440 (JF). The manuscript was partially constructed while JF was visiting at the Institut de 441 Physique du Globe Paris (IPGP).

442 
443

444

445

446

447

448

449

450

451

452

453

454

455

456

457

458

459

460

461

462

463

\section{References}

Antonelli, M.A., Kim, S.-T., Peters, M., Labidi, J., Cartigny, P., Walker, R.J., Lyons, J.R., Hoek, J., Farquhar, J., 2014. Early inner solar system origin for anomalous sulfur isotopes in differentiated protoplanets. Proc. Natl. Acad. Sci. U. S. A. 111, 17749-54. https://doi.org/10.1073/pnas.1418907111

Beaudry, P., Longpré, M.-A., Economos, R., Wing, B.A., Bui, T.H., Stix, J., 2018. Degassinginduced fractionation of multiple sulphur isotopes unveils post-Archaean recycled oceanic crust signal in hotspot lava. Nat. Commun. 9, 5093.

Burgisser, A., Alletti, M., Scaillet, B., 2015. Simulating the behavior of volatiles belonging to the $\mathrm{C}-\mathrm{O}-\mathrm{H}-\mathrm{S}$ system in silicate melts under magmatic conditions with the software DCompress. Comput. Geosci. 79, 1-14.

Cabral, R.A., Jackson, M.G., Rose-Koga, E.F., Koga, K.T., Whitehouse, M.J., Antonelli, M.A., Farquhar, J., Day, J.M.D., Hauri, E.H., 2013. Anomalous sulphur isotopes in plume lavas reveal deep mantle storage of Archaean crust. Nature 496, 490-493. https://doi.org/10.1038/nature12020

Cottaar, S., Romanowicz, B., 2012. An unsually large ULVZ at the base of the mantle near Hawaii. Earth Planet. Sci. Lett. 355, 213-222.

de Moor, J.M., Fischer, T.P., Sharp, Z.D., King, P.L., Wilke, M., Botcharnikov, R.E., Cottrell, E., Zelenski, M., Marty, B., Klimm, K., 2013. Sulfur degassing at Erta Ale (Ethiopia) and Masaya (Nicaragua) volcanoes: Implications for degassing processes and oxygen fugacities of basaltic systems. Geochemistry, Geophys. Geosystems 14, 4076-4108. 
Delavault, H., Chauvel, C., Thomassot, E., Devey, C.W., Dazas, B., 2016. Sulfur and lead isotopic evidence of relic Archean sediments in the Pitcairn mantle plume. Proc. Natl. Acad. Sci. 113, 12952-12956. https://doi.org/10.1073/pnas.1523805113

Dottin, J.W., Farquhar, J., Labidi, J., 2018. Multiple sulfur isotopic composition of main group pallasites support genetic links to IIIAB iron meteorites. Geochim. Cosmochim. Acta 224, 276-281. https://doi.org/10.1016/j.gca.2018.01.013

Fiege, A., Holtz, F., Shimizu, N., Mandeville, C.W., Behrens, H., Knipping, J.L., 2014. Sulfur isotope fractionation between fluid and andesitic melt: an experimental study. Geochim. Cosmochim. Acta 142, 501-521.

French, S.W., Romanowicz, B., 2015. Broad plumes rooted at the base of the Earth's mantle beneath major hotspots. Nature 525, 95.

Frost, D.J., Liebske, C., Langenhorst, F., McCammon, C.A., Trønnes, R.G., Rubie, D.C., 2004. Experimental evidence for the existence of iron-rich metal in the Earth's lower mantle. Nature 428, 409.

Gaillard, F., Scaillet, B., 2009. The sulfur content of volcanic gases on Mars. Earth Planet. Sci. Lett. $279,34-43$.

Graham, D.W., Christie, D.M., Harpp, K.S., Lupton, J.E., 1993. Mantle plume helium in submarine basalts from the Galápagos platform. Science (80-. ). 262, 2023-2026.

Heidel, C., Tichomirowa, M., Junghans, M., 2013. Oxygen and sulfur isotope investigations of the oxidation of sulfide mixtures containing pyrite, galena, and sphalerite. Chem. Geol. 342, 29-43. 
485

486

487

488

489

490

491

492

493

494

495

496

497

498

499

500

501

502

503

504

505
Jackson, C.R.M., Bennett, N.R., Du, Z., Cottrell, E., Fei, Y., 2018. Early episodes of highpressure core formation preserved in plume mantle. Nat. Publ. Gr. 553, 491-495. https://doi.org/10.1038/nature25446

Jackson, M.G., Hart, S.R., Konter, J.G., Kurz, M.D., Blusztajn, J., Farley, K.A., 2014. Helium and lead isotopes reveal the geochemical geometry of the Samoan plume. Nature 514, 355358. https://doi.org/10.1038/nature13794

Jackson, M.G., Hart, S.R., Koppers, A.A.P., Staudigel, H., Konter, J., Blusztajn, J., Kurz, M., Russell, J.A., 2007a. The return of subducted continental crust in Samoan lavas. Nature 448,684 .

Jackson, M.G., Kurz, M.D., Hart, S.R., 2009. Helium and neon isotopes in phenocrysts from Samoan lavas : Evidence for heterogeneity in the terrestrial high $3 \mathrm{He} / 4 \mathrm{He}$ mantle. Earth Planet. Sci. Lett. 287, 519-528. https://doi.org/10.1016/j.epsl.2009.08.039

Jackson, M.G., Kurz, M.D., Hart, S.R., Workman, R.K., 2007b. New Samoan lavas from Ofu Island reveal a hemispherically 264, 360-374. https://doi.org/10.1016/j.epsl.2007.09.023

Johnston, D.T., 2011. Multiple sulfur isotopes and the evolution of Earth's surface sulfur cycle. Earth-Science Rev. 106, 161-183. https://doi.org/https://doi.org/10.1016/j.earscirev.2011.02.003

Kelley, K.A., Plank, T., Farr, L., Ludden, J., Staudigel, H., 2005. Subduction cycling of U, Th, and Pb. Earth Planet. Sci. Lett. 234, 369-383.

Kruijer, T.S., Kleine, T., 2018. No $182 \mathrm{~W}$ excess in the Ontong Java Plateau source. Chem. 
Kurz, M.D., Curtice, J., Fornari, D., Geist, D., Moreira, M., 2009. Primitive neon from the center of the Galápagos hotspot. Earth Planet. Sci. Lett. 286, 23-34.

509

510

Kurz, M.D., Jenkins, W.J., Hart, S.R., Clague, D., 1983. Helium isotopic variations in volcanic rocks from Loihi Seamount and the Island of Hawaii. Earth Planet. Sci. Lett. 66, 388406. https://doi.org/10.1016/0012-821X(83)90154-1

Labidi, J., Cartigny, P., 2016. Negligible sulfur isotope fractionation during partial melting: Evidence from Garrett transform fault basalts, implications for the late-veneer and the hadean matte. Earth Planet. Sci. Lett. 451, 196-207.

Labidi, J., Cartigny, P., Hamelin, C., Moreira, M., Dosso, L., 2014. Sulfur isotope budget (32S, 33S, 34S and 36S) in Pacific-Antarctic ridge basalts: A record of mantle source heterogeneity and hydrothermal sulfide assimilation. Geochim. Cosmochim. Acta 133, 47-67. https://doi.org/10.1016/j.gca.2014.02.023

Labidi, J., Cartigny, P., Jackson, M.G., 2015. Multiple sulfur isotope composition of oxidized Samoan melts and the implications of a sulfur isotope 'mantle array' in chemical geodynamics, Earth and Planetary Science Letters. https://doi.org/10.1016/j.epsl.2015.02.004

Labidi, J., Cartigny, P., Moreira, M., 2013. Non-chondritic sulphur isotope composition of the terrestrial mantle. Nature 501, 208-211. https://doi.org/10.1038/nature12490

Labidi, J., Shahar, A., Le Losq, C., Hillgren, V.J., Mysen, B.O., Farquhar, J., 2016. Experimentally determined sulfur isotope fractionation between metal and silicate 
and implications for planetary differentiation. Geochim. Cosmochim. Acta 175, 181194. https://doi.org/10.1016/j.gca.2015.12.001

Lau, H.C.P., Mitrovica, J.X., Davis, J.L., Tromp, J., Yang, H.-Y., Al-Attar, D., 2017. Tidal tomography constrains Earth's deep-mantle buoyancy. Nature 551, 321.

Macpherson, C.G., Hilton, D.R., Day, J.M.D., Lowry, D., Grönvold, K., 2005. High-3He/4He, depleted mantle and low- $\delta 180$, recycled oceanic lithosphere in the source of central Iceland magmatism. Earth Planet. Sci. Lett. 233, 411-427.

Mandeville, C.W., Webster, J.D., Tappen, C., Taylor, B.E., Timbal, A., Sasaki, A., Hauri, E., Bacon, C.R., 2009. Stable isotope and petrologic evidence for open-system degassing during the climactic and pre-climactic eruptions of Mt. Mazama, Crater Lake, Oregon. Geochim. Cosmochim. Acta 73, 2978-3012. https://doi.org/10.1016/j.gca.2009.01.019

Moore, J.G., Fabbi, B.P., 1971. An estimate of the juvenile sulfur content of basalt. Contrib. to Mineral. Petrol. 33, 118-127.

Moulik, P., Ekström, G., 2016. The relationships between large-scale variations in shear velocity, density, and compressional velocity in the Earth's mantle. J. Geophys. Res. Solid Earth 121, 2737-2771.

Mukhopadhyay, S., 2012. Early differentiation and volatile accretion recorded in deepmantle neon and xenon. Nature 486, 101.

Mundl-Petermeier, A., Walker, R.J., Fischer, R.A., Lekic, V., Jackson, M.G., Kurz, M.D., 2020. Anomalous ${ }^{182} \mathrm{~W}$ in high ${ }^{3} \mathrm{He} /{ }^{4} \mathrm{He}$ Ocean Island Basalts: Fingerprints of Earth's 
core? Geochim. Cosmochim. Acta (in press).

Mundl-Petermeier, A., Walker, R.J., Jackson, M.G., Blichert-Toft, J., Kurz, M.D., Halldórsson, S.A., 2019. Temporal evolution of primordial tungsten-182 and $3 \mathrm{He} / 4 \mathrm{He}$ signatures in the Iceland mantle plume. Chem. Geol. 525, 245-259.

Mundl, A., Touboul, M., Jackson, M.G., Day, J.M.D., Kurz, M.D., Lekic, V., Helz, R.T., Walker, R.J., 2017. Tungsten-182 heterogeneity in modern ocean island basalts. Science (80-. ). 356, 66-69. https://doi.org/10.1126/science.aal4179

Ono, S., Wing, B., Johnston, D., Farquhar, J., Rumble, D., 2006. Mass-dependent fractionation of quadruple stable sulfur isotope system as a new tracer of sulfur biogeochemical cycles. Geochim. Cosmochim. Acta 70, 2238-2252.

Rizo, H., Andrault, D., Bennett, N.R., Humayun, M., Brandon, A., Vlastélic, I., Moine, B., Poirier, A., Bouhifd, M.A., Murphy, D.T., 2019. 182W evidence for core-mantle interaction in the source of mantle plumes. Geochemical Perspect. Lett. 11, 6-11.

Rizo, H., Walker, R.J., Carlson, R.W., Horan, M.F., Mukhopadhyay, S., Manthos, V., Francis, D., Jackson, M.G., 2016. Preservation of Earth-forming events in the tungsten isotopic composition of modern flood basalts. Science (80-. ). 352, 809-812. https://doi.org/10.1126/science.aad8563

Starkey, N.A., Stuart, F.M., Ellam, R.M., Fitton, J.G., Basu, S., Larsen, L.M., 2009. Helium isotopes in early Iceland plume picrites: Constraints on the composition of high 3He/4He mantle. Earth Planet. Sci. Lett. 277, 91-100. 
basalts from Baffin Island and the role of a mixed reservoir in mantle plumes. Nature 424, 57.

Thorne, M.S., Garnero, E.J., Jahnke, G., Igel, H., McNamara, A.K., 2013. Mega ultra low velocity zone and mantle flow. Earth Planet. Sci. Lett. 364, 59-67.

Valbracht, P.J., Staudacher, T., Malahoff, A., Allègre, C.J., 1997. Noble gas systematics of deep rift zone glasses from Loihi Seamount, Hawaii. Earth Planet. Sci. Lett. 150, 399-411.

Wicks, J.K., Jackson, J.M., Sturhahn, W., 2010. Very low sound velocities in iron-rich (Mg, Fe) 0: Implications for the core-mantle boundary region. Geophys. Res. Lett. 37.

Willbold, M., Elliott, T., Moorbath, S., 2011. The tungsten isotopic composition of the Earth's mantle before the terminal bombardment. Nature 477, 195.

Williams, C.D., Mukhopadhyay, S., Rudolph, M.L., Romanowicz, B., 2019. Primitive Helium is Sourced from Seismically Slow Regions in the Lowermost Mantle. Geochemistry, Geophys. Geosystems.

Williams, Q., Garnero, E.J., 1996. Seismic evidence for partial melt at the base of Earth's mantle. Science (80-. ). 273, 1528-1530.

Workman, R.K., Eiler, J.M., Hart, S.R., Jackson, M.G., 2008. Oxygen isotopes in Samoan lavas: Confirmation of continent recycling. Geology 36, 551-554.

Workman, R.K., Hart, S.R., Jackson, M., Regelous, M., Farley, K.A., Blusztajn, J., Kurz, M., Staudigel, H., 2004. Recycled metasomatized lithosphere as the origin of the Enriched Mantle II (EM2) end-member: Evidence from the Samoan Volcanic Chain. 
590 Workman, R.K., Hauri, E., Hart, S.R., Wang, J., Blusztajn, J., 2006. Volatile and trace elements

591 in basaltic glasses from Samoa: Implications for water distribution in the mantle. Earth

592 Planet. Sci. Lett. 241, 932-951. https://doi.org/10.1016/j.epsl.2005.10.028

593 Yuan, K., Romanowicz, B., 2017. Seismic evidence for partial melting at the root of major $594 \quad$ hot spot plumes. Science (80-. ). 357, 393-397.

595 Zhang, Z., Dorfman, S.M., Labidi, J., Zhang, S., Li, M., Manga, M., Stixrude, L., McDonough, 596 W.F., Williams, Q., 2016. Primordial metallic melt in the deep mantle. Geophys. Res. 597 Lett. 43, 3693-3699.

598 Zindler, A., Hart, S.R., 1986. Chemical Geodynamics. Annu. Rev. Earth Planet. Sci. 14, 493599 571. https://doi.org/10.1146/annurev.earth.14.1.493

600

601 